\title{
COMMENTARY
}

\section{Clever glia}

Sonia Spitzer ${ }^{1,2}$, Sylvia Agathou ${ }^{1,2}$ and Ragnhildur Thora Karadottir ${ }^{1,2,3^{*}}$

\begin{abstract}
Twenty years ago glial cells were shown to contribute to neuronal information processing, instead of merely supporting neuronal function, thus challenging the century old neuron doctrine. Due to the lack of appropriate experimental models, however, determining the role of glia in higher brain function and disease has been hampered. In a recent paper, Han and colleagues transplanted human glial progenitor cells into mice; not only does this study pave the way for generations of excellent models to study the physiology and pathophysiology of human glial cells, especially in the age of induced pluripotent stem cells, but more importantly it further challenges the neuron doctrine, since the human-glia transplanted mice turned into better learners. So, are glial cells the ones we owe our intelligence to after all?
\end{abstract}

In neuroscience, the neuron has been in the spotlight of research throughout the past century, mostly as it is considered the sole crucial element of higher brain function. This may come as a surprise, as the more numerous cell types in the brain, the glia cells, are often conveniently forgotten and attract attention only when they cause trouble. Central nervous system glial cells are divided into macroglia (astrocytes and oligodendrocytes) and microglia, the immune cells of the brain. Astrocytes are the most abundant cells in the brain, with extraordinary properties involved in an array of different brain functions. They are found in close contact with the bloodbrain barrier, neuronal synapses, other astrocytes, neural stem cells and oligodendroglia. Thus, they seem to form the central nodes of a highly intricate network of cellular information and communication [1]. Accordingly, their

\footnotetext{
* Correspondence: rk385@cam.ac.uk

${ }^{1}$ Wellcome Trust-MRC Stem Cell Institute, John van Geest Centre for Brain

Repair, University of Cambridge, Cambridge CB3 OES, UK

${ }^{2}$ Department of Veterinary Medicine, University of Cambridge, Cambridge

CB3 OES, UK

Full list of author information is available at the end of the article
}

list of functions is long and ever expanding, including homeostasis, energy supply, synapse formation, maintenance, neuronal progenitor migration guidance, metabolic support, synaptic plasticity, regulation of blood flow and repair of the central nervous system [2].

Astrocytes closely enwrap neuronal synapses, which puts them in the unique position to monitor neuronal activity. Twenty years ago they were shown to respond to neuronal activity by a rise in intracellular calcium that propagated in a calcium wave between astrocytes [3]. In return, this calcium rise in the astrocytes caused a calcium rise in the surrounding neurones $[4,5]$, leading to the modulation of neuronal activity via the astrocytic release of glutamate [4]. This was the first time that glial cells were shown to modulate neuronal activity and granted astrocytes a role in information processing, thus challenging the neuron doctrine. In the course of the next two decades, more studies supported the notion of glial cells taking an active role in neuron-glia communication. It was found that transmitter release is a form of communication available not only to neurons; astrocytes are able to release 'gliotransmitters', such as glutamate, D-serine, gamma-aminobutyric acid and ATP or cytokines like TNF alpha, as a response to increased intracellular $\mathrm{Ca}^{2+}[6]$. In recent years, however, the extent to which astrocytes can modulate neuronal function has been debated. Conflicting results and the lack of advanced experimental tools made it difficult to develop a general model of glia-neuron interaction (please see excellent reviews on the topic [7-11]). A recent paper by Han and colleagues [12] circumvented these experimental limitations by transplanting human glial stem/progenitor cells into immunodeficient mice, which mainly differentiated into astrocytes, and thus unveiled their astonishing role in higher cognitive function.

In humans, astrocytes are different and some types of astrocytes are exclusively found in the human brain [2] In general, they are not only bigger in size with longer processes but also their intrinsic and intra-astrocytic signalling, mediated through travelling calcium waves, is three times faster compared to their murine counterparts [12]. In the chimeric mice of Han and colleagues [12], the 
human astrocytes maintained their innate complex characteristics. Despite their different origin and their much larger size, the human cells actively interacted with murine astrocytes and modulated the murine neural network. Excitatory synaptic transmission was highly potentiated in the human-glia chimeric mice via the release of TNF alpha by the human astrocytes, which in turn led to increased membrane trafficking of the GluA1 subunit of the AMPA glutamate receptor. Accordingly, during various behavioural tasks, such as the fear conditioning test, the Barnes maze test and Object-Location Memory task, the human-glia chimeric mice outperformed both the control mice and their murine-glia chimeric counterparts. This work, along with recent reports [13,14], clearly demonstrates that astrocytes can modulate the neuronal network in all its complexity. These findings call for a shift from the neuron doctrine towards an updated view of the neuron-glia interaction in neuron transmission, leaving the exact mechanistic details for future work to reveal.

The ingenuity of the study of Han and colleagues lies in the development of a model to study human glial cells in a 'natural' environment. This model, together with the current fine ex vivo and in vitro experimental approaches focusing on individual astrocyte-synapse relations [11], will hopefully provide a clearer understanding of this glimpse into the exciting world of astrocytes. Especially in the age of induced pluripotent stem cells, in which astrocytes can be generated from somatic cells taken from either healthy individuals or patients with neurological disorders, the possible combination of 'the Han glia model' with transplantation of induced pluripotent stem cell-derived human glia [15] (thus bypassing culturing difficulties surrounding the astrocytic field [16]) holds a great potential for unveiling the role of glial cells in brain malfunction. Therefore, Han and colleagues [12] have not only presented a 'glia milestone' with the demonstration of the profound effects of astrocytes on higher brain functions, but also generated an experimental glial model that will make it possible to study the physiology and pathophysiology of human glial cells.

\section{Abbreviations}

TNF: tumour necrosis factor.

\section{Competing interests}

The authors declare that they have no competing interests.

\section{Author details}

'Wellcome Trust-MRC Stem Cell Institute, John van Geest Centre for Brain Repair, University of Cambridge, Cambridge CB3 OES, UK. ${ }^{2}$ Department of Veterinary Medicine, University of Cambridge, Cambridge CB3 OES, UK.

${ }^{3}$ Department of Psychology, University of Oslo, Oslo, Norway.

\section{References}

1. Barres BA: The mystery and magic of glia: a perspective on their roles in health and disease. Neuron 2008, 60:430-440.

2. Oberheim NA, Wang X, Goldman S, Nedergaard M: Astrocytic complexity distinguishes the human brain. Trends Neurosci 2006, 29:547-553.

3. Cornell-Bell AH, Finkbeiner SM, Cooper MS, Smith SJ: Glutamate induces calcium waves in cultured astrocytes: long-range glial signaling. Science 1990, 247:470-473.

4. Parpura V, Basarsky TA, Liu F, Jeftinija K, Jeftinija S, Haydon PG: Glutamatemediated astrocyte-neuron signalling. Nature 1994, 369:744-747.

5. Nedergaard M: Direct signaling from astrocytes to neurons in cultures of mammalian brain cells. Science 1994, 263:1768-1771.

6. Volterra A, Meldolesi J: Astrocytes, from brain glue to communication elements: the revolution continues. Nat Rev Neurosci 2005, 6:626-640.

7. Hamilton NB, Attwell D: Do astrocytes really exocytose neurotransmitters? Nat Rev Neurosci 2010, 11:227-238.

8. Nedergaard M, Verkhratsky A: Artifact versus reality - how astrocytes contribute to synaptic events. Glia 2012, 60:1013-1023.

9. Halassa MM, Haydon PG: Integrated brain circuits: astrocytic networks modulate neuronal activity and behavior. Annu Rev Physiol 2010, 72:335-355

10. Agulhon C, Petravicz J, McMullen AB, Sweger EJ, Minton SK, Taves SR, Casper KB, Fiacco TA, McCarthy KD: What is the role of astrocyte calcium in neurophysiology? Neuron 2008, 59:932-946.

11. Rusakov DA, Zheng K, Henneberger C: Astrocytes as regulators of synaptic function a quest for the Ca2+ master key. Neuroscientist 2011, 17:513-523.

12. Han X, Chen M, Wang F, Windrem M, Wang S, Shanz S, Xu Q, Oberheim NA, Bekar L, Betstadt S, Silva AJ, Takano T, Goldman SA, Nedergaard M: Forebrain engraftment by human glial progenitor cells enhances synaptic plasticity and learning in adult mice. Cell Stem Cell 2013, 12:342-353.

13. Saab AS, Neumeyer A, Jahn HM, Cupido A, Šimek AAM, Boele H-J, Scheller A, Meur KL, Götz M, Monyer H, Sprengel R, Rubio ME, Deitmer JW, Zeeuw CID, Kirchhoff F: Bergmann glial AMPA receptors are required for fine motor coordination. Science 2012, 337:749-753.

14. Gourine AV, Kasymov V, Marina N, Tang F, Figueiredo MF, Lane S, Teschemacher AG, Spyer KM, Deisseroth K, Kasparov S: Astrocytes control breathing through $\mathrm{pH}$-dependent release of ATP. Science 2010, 329:571-575.

15. Wang S, Bates J, Li X, Schanz S, Chandler-Militello D, Levine C, Maherali N, Studer L, Hochedlinger K, Windrem M, Goldman SA: Human iPSC-derived oligodendrocyte progenitor cells can myelinate and rescue a mouse model of congenital hypomyelination. Cell Stem Cell 2013, 12:252-264.

16. Foo LC, Allen NJ, Bushong EA, Ventura PB, Chung W-S, Zhou L, Cahoy JD, Daneman R, Zong H, Ellisman MH, Barres BA: Development of a method for the purification and culture of rodent astrocytes. Neuron 2011, 71:799-811.

doi:10.1186/scrt311

Cite this article as: Spitzer et al.: Clever glia. Stem Cell Research \& Therapy 2013 4:100. 